\title{
ÉTICA NA ESCOLA: (RE)ACENDENDO UMA POLÊMICA
}

\author{
Renato José de O liveira*
}

RESU M 0 : C onsiderando que a ética na escola e a formação do caráter do aluno têm sido discutidas em todo mundo, este artigo trata o tema com baseem três eixos. 0 primeiro apresenta al gumas visões filosóficas de ética e de moral, buscando investigar se as distinções teóricas têm ou não significado social. 0 segundo eixo se relaciona aos fundamentos da ética eda moral como disciplinas práticas. A principal questão colocada é: os princípios gerais devem legitimar os juízos de valor éticos/morais ou vice-versa? Finalmente, éabordado o papel cumprido pela escola na formação ética/moral do cidadão. C ertas concepções educacionais como a de Comênio, a de $D$ ewey e também as práticas pedagógicas homogeneizadoras, assim como as propostas relativas à ética presentes nos Parâmetros Curriculares N acionais, são discutidas.

Palavras-chave: Ética na escola; Formação do caráter; Princípios éticos/ morais; Argumentação; Parâmetros Curriculares N acionais.

\section{Introdução}

A ética na escola vem sendo a menina dos olhos de muitos educadores em todo o mundo. H oje em dia, é possível encontrar na Internet vários sites em que 0 assunto é tratado por meio de resoluções, manifestos, ensaiOS, enfim, de uma variada gama de documentos. 0 Center for the Advancement of Ethics and Character, com sede em Seattle, Estados Unidos, aponta, por exemplo, em um manifesto (1999, p. 1), que o aumento dos índices de violência, de suicídio e de gravidez precoce entre adolescentes tem tomado de assalto a sociedade norteamericana nos últimos anos. Em vista disso, propõe que as escolas e os professores reafirmem suas responsabilidades como formadores de caráter. Já no Brasil, o capítulo dos PCN s (terceiro e quarto ciclos) relativo à ética sublinha a necessidade de a

* Professor da U niversidade Federal do Rio de Janeiro (UFRJ) e pesquisador do CN Pq. E-mail: renato@montreal.com.br 
escola se configurar em espaço de reflexão sobre a moralidade porque, entre outras razões, "o cotidiano escolar está encharcado de valores que se traduzem em princípios, regras, ordens, proibições" (1998, p. 24).

0 presente artigo busca, então, examinar três eixos centrais que permeiam essa temática:

1. O significado social da distinção entre ética e moral.

2. A relação entre os princípios éticos (morais) e os juízos de valor.

3. 0 papel da escola na formação ética (moral) do cidadão.

$\mathrm{N}$ aturalmente, cada um desses eixos abarca inúmeras questões, constituindo-se em campos abertos à polêmica, de sorte que as discussões aqui apresentadas não têm a pretensão de dar respostas voltadas para aplicações imediatas, quer por parte dos professores em suas salas de aula, quer por parte das instituições escolares.

\section{Ética emoral: repensando asfronteiras}

D urante os anos sombrios do regime militar, as escolas brasileiras de primeiro e de segundo grau pouco falavam de ética. Aliás, esse termo, juntamente com expressões do tipo "educação para a cidadania" ou "exercício da reflexão crítica", se achava praticamente ausente do vocabulário pedagógico de uso mais comum. A formação do caráter dos alunos ficava, sobretudo, a cargo da disciplina M oral e Cívica, em geral detestada pelos estudantes. Lembro-me bem do bordão "M obral e Cínica", que no início da década de 1970, quando então eu cursava a sétima série do primeiro grau, anunciava, nos corredores do colégio, o início daquelas aulas maçantes nas quais a exortação anticomunista era sempre a tônica.

O s tempos mudaram e hoje a abordagem das questões éticas/ morais não mais assume 0 caráter de cruzada santa movida contra um inimigo assustador, mas, para usar uma expressão de Paulo Freire, constitui-se em um "a favor de alguém". Trata-se de somar esforços em prol da formação de um cidadão consciente dos seus direitos e deveres. Entretanto, que tipo de indivíduo se quer efetivamente formar? U m sujeito ético ou um sujeito moral?

O s PCN s fazem claramente a opção pelo sujeito ético, embora afirmem que a moral é algo inerente à cultura, abrangendo todas as instâncias da vida social (idem, p. 23). 0 caráter histórico, - que confere à moral a dimensão da temporalidade - e a multiplicidade das dou- 
trinas e das concepções que norteiam as ações morais são, sem dúvida, mencionados no documento, mas a preferência pela ética como tema transversal se dá na medida em que esta é definida como "reflexão crítica sobre a moralidade" (ibid.).

A clara e segura demarcação de fronteiras entre 0 que pertence ao domínio da moral e o que corresponde à ética está longe de ser objeto de consenso entre os filósofos. Descartes, no Discurso do método, fala, por exemplo, em uma moral provisória que deveria reger a conduta por meio de algumas poucas máximas ou princípios basilares. Para ele, a provisoriedade se justificava pelo fato de que o método para bem dirigir a razão ainda não tinha condições de ser aplicado ao campo da moralidade, sendo então necessário adotar uma "casa" temporária, na qual fosse possível viver enquanto durassem os trabalhos de construção da moradia definitiva, isto é, da moral universal e verdadeira (D escartes, 1996, p. 27).

D o ponto de vista cartesiano, a historicidade não permeia a moral, posto que a meta maior é estabelecer um absoluto, o qual, pela própria natureza dos absolutos, é eterno, intemporal. Este teria a prerrogativa de prescrever as formas de conduta dignas do homem de bem sem que houvesse margem para dúvidas. $M$ as é interessante notar que a construção provisória levada a cabo pelo filósofo não dispensa a reflexão crítica, como se pode observar na discussão feita acerca do primeiro princípio (seguir os costumes e leis do próprio país e também as opiniões mais moderadas):

E, entre as várias opiniões igualmente aceitas, só escolhia as mais moderadas; não só porquesão sempreas mais cômodas para a prática, everossimilmenteas melhores, poistodo excesso costuma ser mau, mastambém afim demeafastar menos do verdadeiro caminho, caso meenganasse, do quese, tendo escol hido um dos extremos, 0 outro devesse ser seguido. (I dem, p. 28)

Pensar, refletir, ponderar, medir os próprios passos são, portanto, condições necessárias a um bom moralista. ${ }^{1}$

0 utro pensador que buscou enfatizar o caráter reflexivo e investigativo da moral foi John D ewey. Falando acerca da necessidade de se abandonarem antigas concepções, 0 autor chamava a atenção para a perspectiva de criação de novos métodos, os quais teriam por objetivo mostrar que "a moral não é um catálogo de atos, nem um conjunto de regras a serem aplicadas, tal como acontece com prescrições médicas ou receitas culinárias" (D ewey, 1958, p. 170). D ewey desejava fornecer à moral o mesmo estatuto de cientificidade das ciências naturais, entendendo que nem estas nem aquela possuíam compromissos com as verdades absolutas. Tratava-se de medir o valor de uma verdade em razão do seu 
alcance social, o que implica dizer que são os homens - e não instâncias transumanas como D eus ou a Razão U niversal - os responsáveis pela legitimação dos saberes mais significativos para si mesmos.

Já segundo André Lalande (1993, p. 349), é à ética que se deve conferir o estatuto de cientificidade, na medida em que ela estabelece juízos de apreciação sobre as ações merecedoras dos qualificativos "bom" e "mau". Para ele, qualquer princípio referente à moral - previamente definida como conjunto de prescrições assumidas em determinado período histórico e em determinado contexto social e também como exortação e conformação a tais preceitos - é suscetível às valorações humanas, as quais se aplicam a fatos concretos relativos à conduta. Lalande afirma ainda que o chamado idealismo alemão (Kant, Schelling, $\mathrm{H}$ egel) tendeu a situar a ética em um patamar mais el evado que a moral, o que explicaria, no âmbito da filosofia, certa preferência pelo estudo da primeira.

Autores pós-modernos, porém, se inclinam por caracterizar a moral como algo que marcou de forma bem mais decisiva os caminhos da modernidade. M affesoli (1994), por exemplo, considera morais os modelos de conduta que têm pretensões à universalidade. A Revolução Francesa teria sido um movimento que permitiu a difusão de uma certa moral, a burguesa, para o conjunto da humanidade. Em virtude disso, 0 autor prefere atribuir à ética caráter mais restrito, tomando-a como instância relativa aos costumes e à conduta de grupos ou facções. Um caso típico seria a M áfia, organização cujo comportamento é condenado pela moral burguesa vigente nas sociedades contemporâneas, mas que possui uma ética própria, seguida por seus integrantes. M affesoli entende que os diferentes sistemas morais (burguês, proletário, cristão etc.) se acham ancorados em metanarrativas que se esvaziam tão logo os projetos redentores e emancipadores da humanidade dão mostras de seu esgotamento. Emergem, então, as éticas grupais, regidas fundamentalmente pela estética ${ }^{2}$ e não por uma razão totalizante que negligencia os microfenômenos da existência social de acordo com um quadro explicativo macroestrutural.

Em face do que foi discutido acerca das caracterizações de ética e de moral, cabe perguntar até que ponto a distinção entre elas adquire importância social, tendo em vista os maiores interessados: os sujeitos concretos que agem no mundo. Tomando, por exemplo, o caso dos adolescentes que atearam fogo a um índio pataxó alguns anos atrás em Brasília, é mais relevante dizer que deixaram de se comportar como sujeitos éticos ou que abdicaram da condição de sujeitos morais? A menos que se tenha predileção pelas discussões bizantinas, o enqua- 
dramento teórico do ato é extremamente secundário diante da ação praticada. 0 que está em jogo em episódios desta natureza é toda uma visão de mundo construída sobre hábitos, costumes, crenças e valores que permitem colocar o outro, o diferente, na situação de brinquedo manipulável por quem se julga superior a ele. Portanto, mais significativa que a distinção entre sujeitos éticos e sujeitos morais é a discussão acerca das tensões entre identidade e alteridade, a qual remete para a problemática da relação entre os princípios éticos/morais e os juízos de valor.

\section{Princípios ejuízos: quem legitima quem?}

A tradição filosófica e científica do 0 cidente tem se pautado por buscar os princípios fundadores dos sistemas de conhecimento propostos à humanidade. Uma vez determinados, os princípios seriam os pontos de partida seguros, transparentes, inequívocos que permitiriam à razão deduzir as leis válidas para os casos gerais, explicar desvios verificados em casos particulares e prever desdobramentos futuros. Os sistemas em questão deveriam ser imunes à temporalidade, isto é, ao crivo da história: uma vez estabelecidos, valeriam para todo o sempre. No máximo, sofreriam pequenos ajustes que em nada alterariam sua essência, visto que foram construídos sobre axiomas verdadeiros e universais.

Contrapondo-se a esse tipo de busca, os céticos apontaram os problemas relativos às determinações de tal natureza. No início da era cristã, Agripa, por exemplo, invocava os modos da regressão ao infinito e do postulado para mostrar a fragilidade desses empreendimentos. Pelo primeiro modo, exigia que as provas fornecidas acerca de uma dada afirmação fossem provadas, o que implicaria regredir infinitamente sem nunca chegar à prova cabal e decisiva (o princípio fundador). Pelo segundo, recusava que determinada prova fosse aceita como ponto de partida inquestionável pelo simples fato de ser indemonstrável: por que seria ela e não outra qualquer o princípio fundador?

0 argumento cosmológico ou via da causalidade eficiente, proposto por Tomás de Aquino, precisou recorrer a Deus para afirmar a existência de uma causa superior a todas as demais. Baseando-se em Aristóteles, Tomás partiu da consideração de que, não existindo efeito sem causa, tudo no universo se ordena segundo uma rede de causalidade do tipo: causa primeira $\rightarrow$ causa intermediária $\rightarrow$ causa final. Se a causa primeira não existisse, as demais forçosamente deixariam de existir, o 
que seria absurdo. Logo, haveria uma causa eficiente suprema, cuja existência seria absolutamente necessária: D eus, princípio de todos os princípios. Situando a discussão nestes termos, Tomás só deixou ao cético a opção de negar a existência de D eus, o que significava remeter um problema epistemológico para o campo da teologia.

Essas considerações também se aplicam à ética/moral. Como salienta Perelman (1996, p. 288):

Se partirmos da hipótese de que D eus é o Ser supremo, cuja vontade é 0 fundamento detodanormamoral, afilosofia moral não existecomo disciplina independente: dependeinteiramenteda teologia. M as, senosempenhamos em elaborar uma ética independente, surge imediatamente o problema de seu fundamento, queéaindamais controvertido porqueopiniõesopostassemanifestaram sobre o ponto de saber o que deve ser fundamentado e o que deve servir defundamento.

$\mathrm{N}$ a esteira da revolução científica moderna, o pensamento filosófico, desejando se manter independente da teologia, buscou outros absolutos que pudessem cumprir o mesmo papel cumprido pelo divino. A razão foi, sem dúvida, um dos preferidos. A natureza do princípio fundador passaria a ser então racional, subordinando a vontade, ainda que esta fosse a do Ser supremo, pois mesmo ela não poderia se opor a algo como uma legislação universal. É nisso que se baseia o imperativo categórico de Kant (1997, p. 42): "Age de tal modo que a máxima da tua vontade possa valer sempre ao mesmo tempo como princípio de uma legislação universal".

Ainda que a vida dos homens os coloque diante de situações em que as razões individuais julgam e fazem escolhas, o imperativo ético/ moral permanece inabalável. Tomando como exemplo o caso hipotético descrito nos PCN s (op. cit., p. 20) - a fim de salvar um doente, roubar ou não um remédio cujo preço é proibitivo para o necessitado -, o conflito entre os valores vida e propriedade seria, de um ponto de vista kantiano, solucionado pela obediência à lei maior, universal, que prescreve não roubar. O bserva-se que a contingência, ainda que dramática, não pode ser colocada em um plano superior à generalidade, pois aí se abre um perigoso precedente: uma vez excepcionalmente admitido, o roubo passa a ter seu caráter intrinsecamente mau diminuído pela incorporação de certos atenuantes, pondo em risco a universalidade da própria prescrição. 0 princípio ético/moral fundador é, portanto, de natureza deontológica, situando o rigor do formalismo acima de quaisquer eventos que ocorram no plano dos seres concretos (plano ontológico). 
Ele legitima os juízos de valor (no exemplo em questão, atribuir primazia ao respeito à propriedade privada) concernentes à realidade vivida, na medida em que se apresenta como modelo transempírico, como norma máxima, inequívoca porque perfeita.

O utros princípios fundadores de caráter deontológico têm marcado os sistemas éticos/morais pós-kantianos. Um deles é a conhecida formulação utilitarista "fazer sempre o que é mais útil ao maior número de indivíduos". Aqui não se apela para uma legislação universal, mas para os critérios de utilidade e quantidade concebidos como absolutos. Bentham (1974) julgava que sendo os homens governados por dois senhores, o prazer e a dor, o útil seria o resultado de um cálculo que expressasse a maior soma possível do primeiro e a menor soma possível da segunda. M as como esse cálculo é singular para cada indivíduo, seria preciso considerá-lo em termos sociais, tendo em vista o critério de maioria.

Sem dúvida, é difícil aceitar que sentimentos como o prazer e a dor possam ser expressos por alguma medida suscetível de cálculo, de sorte que, colocada nestes termos, a noção do útil apresentada por Bentham se torna um alvo fácil para a crítica. Por sua vez, o critério do maior número também pode ser questionado porque se alicerça sobre uma concepção aritmética: a sociedade é vista como somatório de seres autônomos, atomizados, independentes. O s antagonismos gerados por diferentes interesses sociais e os embates políticos deles decorrentes, que fazem os conceitos de maioria e de minoria escaparem ao critério puramente numérico, não se constituem em objeto de exame para a ética/moral utilitarista. O utra crítica interessante, que salienta 0 ufanismo hedonista das concepções de Bentham, é feita por Dewey (op. cit., p. 181), cujas idéias são muitas vezes confundidas com as dos utilitaristas:

M as, a ordem econômica do capitalismo, quesucediaà feudal, trouxe consigo seus próprios males sociais, e alguns desses males cuidou o utilitarismo de defendê-los ou dissimulá-los. A reverência à aquisição eà posse de prazeres tomou um caráter sinistro à base do imenso desejo hodierno pelariqueza material epelos prazeresqueessa riqueza torna possíveis.

Se D ewey tem razão quando afirma que o utilitarismo de Bentham se alinha aos objetivos do capitalismo, seria difícil imaginar que, aplicando o princípio da máxima utilidade para o maior número, alguém pudesse legitimar um juízo de valor contrário à preservação da propriedade privada. No caso do remédio, o utilitarista prescreveria que o roubo não fosse feito por implicar, para o ladrão, problemas que reduziriam 
sua soma de prazeres, aumentando a das dores. Por vias diferentes, chegar-seia então à mesma conclusão quanto à ação prática.

Visto que os princípios fundadores não se acham ao abrigo dos questionamentos, caberia então dizer que o caminho a ser seguido é 0 inverso, ou seja, legitimar princípios éticos/morais com base em juízos de valor particulares? Tal procedimento, desenvolvido à maneira das ciências indutivas, parte dos julgamentos feitos acerca de situações específicas para atingir princípios gerais que comporiam uma espécie de senso comum ético/moral capaz de orientar juízos futuros. Essa posição filosófica, defendida por Lévy-Bruhl (apud Perelman, op. cit., p. 289-291), ${ }^{3}$ enfatiza que "as morais teóricas divergem, ao passo que as morais práticas coincidem", sendo portanto mais propícias ao estabelecimento dos princípios buscados.

Essa posição pode ser criticada pelas próprias limitações dos métodos indutivos na produção do conhecimento. Como assinalou H ume (1950), toda indução tem por fundamento o hábito ou o costume de se esperar que 0 evento $X_{1}$, semelhante a $X$, se processe da mesma maneira. $M$ as 0 hábito é apenas uma crença que se sedimenta pela repetição, não podendo ser racionalmente explicado. Assim, se os axiomas estabelecidos por via indutiva sempre correm o risco de serem minados por casos particulares que se configurem em contra-exemplos capazes de forçar até, em termos kuhnianos, uma mudança de paradigma, risco maior correm os princípios éticos/morais, os quais não são da mesma natureza que os axiomas científicos. Estes têm caráter unívoco, ou seja, explicam rigorosamente do mesmo modo os casos semelhantes, enquanto aqueles não podem pretender o mesmo nível de rigor, pois o próprio enquadramento na categoria de semelhança requer acordos mais difíceis de celebrar. Assim, se em n casos de doença grave os remédios caros fossem roubados e os enfermos salvos, poder-se-ia chegar ao seguinte princípio ético/moral: o roubo está autorizado toda vez que um remédio de alto custo não puder ser comprado pelo doente. $\mathrm{N}$ ão é preciso ir muito longe para perceber os problemas que tal princípio geraria: na impossibilidade de medir com os mesmos parâmetros a gravidade das doenças, o risco de vida dos pacientes e 0 poder aquisitivo deles, como garantir que os casos ditos semelhantes eram efetivamente semelhantes?

U ma saída para os impasses criados pela multiplicidade de juízos de valor é tentada por $\mathrm{H}$ abermas, para quem é possível explicar o valor prescritivo das normas de convivência com base em processos argumentativos que deixem os valores fora da discussão. A ética do discurso proposta pelo autor fundamenta-se em um princípio de natureza deonto- 
lógica (princípio D) expresso nos seguintes termos: "só podem reclamar validade as normas que encontrem (ou possam encontrar) 0 assentimento de todos os envolvidos, estando estes na condição de participantes de um discurso prático" (H abermas, 1990, p. 66).

Segundo $H$ abermas, o princípio $D$ é uma conseqüência, no campo da ética, de um outro mais geral, chamado princípio de universalização (U ), o qual se coloca como regra de argumentação que torna possível o consenso em discursos práticos:

Todos os envolvidos podem aceitar as conseqüências eos efeitos colaterais cuja observância geral pode ser antecipada para satisfazer os interesses de cada um (e tais conseqüências são preferíveis em relação a outras possi bilidadesalternativas deregulação). (Idem, p. 65)

$\mathrm{O}$ que $\mathrm{H}$ abermas pretende frisar é que, uma vez tendo aceitado participar de um processo argumentativo, todos os afetados por determinada questão devem estar cientes de que os desdobramentos de tal processo são sempre preferíveis a outras soluções - a imposição, a violência etc. - passíveis de serem aplicadas. Com isso, o autor acredita manter seu princípio a salvo da crítica céptica, pois para questionar a validade da argumentação como prática reguladora, o céptico precisaria fornecer algum argumento contrário, o que implicaria, para ele, incorrer em uma contradição performativa: negar a argumentação por meio de outra argumentação.

O s princípios U e $\mathrm{D}$ encarnam uma pragmática-transcendental, na medida em que se propõem a regular universalmente os discursos práticos que envolvem a elaboração das normas sem, no entanto, buscar justificá-las como boas ou más, justas ou injustas. Assim sendo, a ética do discurso tem por objeto o contexto (que é processo) e não o conteúdo material das normas (resultado final).

A proposta habermasiana representa um inegável esforço para manter algum tipo de formalismo como fundamento da ética/moral em um tempo em que as epistemologias fundacionais e os a priori metafísicos sofrem um pesado revés. ${ }^{4}$ Todavia, até que ponto tal proposta é significativa para os seres concretos que, vivendo no mundo sem poder abdicar das paixões e dos juízos de valor, têm necessidade de uma ética/moral que diga respeito à facticidade na qual estão imersos?

O s princípios éticos/morais só adquirem significado prático quando o caráter abstrato e geral que possuem é confrontado com o conteúdo concreto da realidade vivida. Em vista disso, não importa muito saber 
qual a origem de um princípio do tipo: não faças ao outro aquilo que não gostarias que fizessem a ti (regra de ouro). Tal máxima foi formulada pela razão? D itada pela religião? Estabelecida com base em experiências de vida? Aqui também a discussão assume um indisfarçável sabor escolástico, pois o que tem significado social são os conteúdos concretos das prescrições "não fazer" e "não gostar". Estes, naturalmente, sofrem grandes variações conforme a história e a cultura das sociedades, mas é justamente a partir do embate entre 0 factual e o genérico, entre o concreto e 0 abstrato que se pode chegar às normas éticas/morais. É exatamente isso que Perelman (op. cit., p. 293) sugere:

Porque os princípios de moral não possuem a univocidade dosaxiomas mate máticose osjuízos morais não são nem tão seguros, nem tão facilmentecomunicáveis quanto os juízos deexperiência, as relações que mantêm entresi, que são relações dialéticas, serão mais bem compreendidasseas aproximarmosnão das ciências exatas ou naturais, mas do D ireito e de sua aplicação.

$\mathrm{N}$ ão sendo dedutiva, indutiva nem isenta de juízos de valor, a ciência do Direito é um modelo mais flexível. À semelhança do que ocorre nos processos jurídicos, as discussões que estabelecem as normas éticas/morais podem ser reabertas quando novos elementos surgirem. A dialética de que fala Perelman sugere uma tensão constante entre a prescrição e a facticidade, impedindo tanto a primeira de adquirir a rigidez de uma estátua, quanto a segunda de declarar o valetudo sem fronteiras. Voltando, então, à situação do roubo do remédio, poder-se-ia dizer que, de acordo com a regra de ouro, a pessoa não deveria praticá-lo, posto que, tal como o dono da farmácia, também não gostaria de ser privada de um pertence seu. Já segundo o juízo de valor do praticante da ação, por ter evitado a morte de um ente querido, o roubo seria considerado ético.

Para fugir ao reducionismo das respostas sumárias do tipo isso é certo e isso é errado, é preciso reconhecer que a questão já não pertence apenas aos três envolvidos (o enfermo, o ladrão e o lojista), mas a grupos sociais distintos: os comerciantes, as comunidades carentes, a própria nação etc.

Tomando por base a teoria da argumentação desenvolvida por Perelman e O lbrechts-Tyteca (1996), as questões éticas/morais podem ser vistas como matéria integrante dos processos dialógicos que envolvem diferentes oradores e diferentes auditórios. Segundo os dois autores (idem, p. 41-42), os processos dialógicos são tipificados em heurísticos e erísticos. No primeiro caso, os interlocutores buscam as boas razões 
que podem levar a um veredicto comum, a um consenso sobre o que é discutido. 0 diálogo assume caráter francamente amistoso, já que não haveria outro interesse em jogo além de encontrar a melhor solução para questões controversas. N o segundo caso, os interlocutores se colocam como adversários que desejam o triunfo das teses defendidas. 0 objetivo de cada orador é convencer um terceiro (situado na condição de juiz) de que seu discurso contempla a melhor causa. 0 diálogo assume então um caráter de disputa, típico dos debates políticos e jurídicos.

$\mathrm{N}$ a medida em que, em qualquer discussão prática, os argumentos utilizados nunca deixam de expressar interesses, valores e convicções dos oradores, as formas heurísticas tendem a ficar mais distantes da realidade do que as erísticas. Entretanto, seria um erro pensar que todo diálogo é apenas disputa e dissenso, pois há situações em que, na ausência de certos acordos, é impossível estabelecer níveis mínimos de convivência. Por outro lado, a legitimação de uma tese por um dado auditório, ainda que possuidor de prestígio social, não implica a aceitabilidade incondicional dessa tese. Embora os auditórios particulares muitas vezes tendam a ver a si mesmos como encarnação do auditório universal - cujo veredicto seria inquestionável -, outros auditórios estarão sempre a questioná-los:

Acreditamos, pois, queos auditóriosnão são independentes, quesão auditórios concretos particulares quepodem impor uma concepção deauditório universal quelheséprópria; mas, em contrapartida, éo auditório universal não definido que é invocado para julgar da concepção do auditório universal própria de determinado auditório concreto, para examinar, a um só tempo, o modo como écomposto, quais os indivíduos que, conformeo critério adotado, o integram e qual al legitimidadedessecritério. Pode-sedizer que osauditóriosjulgam-seuns aos outros. (I bid., p. 39)

A argumentação encarnada no contexto histórico-social e dirigida a homens plenos - formados por faculdades volitivas, racionais e emotivas (Perelman, 1988, p. 26) - não é nenhuma panacéia universal, mas um caminho mais promissor que as respostas sumárias ou que o uso da violência para se chegar a soluções éticas/morais aceitáveis.

\section{A escola e a formação ética/moral do cidadão}

A concepção moderna de escola nasce com Comênio, no século XVII, opondo-se tanto à ineficiência quanto à elitização de um ensino marcado pela tradição escolástica. Fascinado pelo advento da tipografia e das novas técnicas de produção utilizadas nas manufaturas, o bispo 
morávio pensava a escola como "oficina de homens" (Comênio, 1997, p. 104) capaz de dar aos educandos um conjunto de saberes sólidos, desenvolver as mais elevadas virtudes e sedimentar a mais sincera fé cristã.

Partidário das teorias do conhecimento de base empirista, Comênio vislumbrava a possibilidade de moldar desde cedo a tábua rasa que para ele era a mente humana, defendendo, por conseguinte, o início da educação escolar nos primeiros anos da infância. Trabalhando sobre uma "cera" ainda não enrijecida pelos vícios e pelos anos e, além disso, tendo ao seu dispor os métodos de ensino adequados, o professor poderia imprimir nos intelectos os conhecimentos desejáveis, tal como 0 tipógrafo imprime letras no papel.

A metáfora comeniana, insustentável perante os saberes que mais tarde foram construídos acerca da psique humana, sofre, entretanto, apenas uma readequação em tempos posteriores: de folha de papel em branco, a mente do al uno passa a ser vista como "folha de papel suja", na qual se acham impressos conhecimentos errôneos. Ao professor cabe, então, apagar ou limpar as concepções prévias (misconceptions) e inserir o que é "correto", os conteúdos das disciplinas escolares (M azzotti \& Oliveira, 2000, p.13).

$\mathrm{N}$ a medida em que o processo educativo moderno é marcado pela metáfora do professor-modelador, quem deveria ser modelado? Para Comênio era necessário não só aumentar o número de escolas, como também franquear a todos - ricos, pobres, meninos, meninas e mesmo portadores de certo retardamento mental - as mais amplas oportunidades educacionais. Assim, 0 autor da Didática M agna conferia à escola 0 dever ético/moral de incluir aqueles que a má sorte ou, sobretudo, a negligência dos homens colocara na condição de párias da sociedade.

$\mathrm{N}$ ão tendo o objetivo de questionar as relações de mando-obediência entre governantes e governados ou entre eclesiásticos e fiés, Comênio acreditava que o mundo se tornaria mais conforme a vontade do Criador se quem mandasse o fizesse com doçura e se quem obedecesse seguisse as ordens de boa vontade e não por medo ou por espírito de subserviência.

Trata-se, portanto, de uma pedagogia que, a despeito dos fundamentos mecanicistas, pretende integrar de modo harmônico os ensinos intelectual, ético/moral e religioso, sem, por exemplo, privilegiar o primeiro em relação aos outros dois: "infeliz instrução a que não se converte em moralidade e piedade! E o que é a sabedoria sem a virtude? (...) a instrução no homem que se aparta das virtudes é como jóia de ouro em focinho de porco" (idem, p. 100). 
A crítica às concepções pedagógicas que vêem o professor como modelador do intelecto e do caráter do aluno é feita pelo pensamento escolanovista, o qual tem por perspectiva promover uma verdadeira revolução copernicana na escola. Situado como centro, como Sol do processo educativo, o professor é investido de poder e de saber quase absolutos, enquanto para os alunos são reservadas posições periféricas, de astros sem luz que gravitam em torno do mestre, recebendo ensinamentos de forma passiva. $M$ as a quem efetivamente serve a escola?

D ewey e seus seguidores respondem que os papéis estão invertidos, ou seja, a centralidade deve caber ao aluno, o que significa dizer: os interesses e inclinações discentes constituem o foco principal do trabaIho pedagógico. M as de nada adianta propor uma nova "astronomia" escolar se os métodos tradicionais de ensino - centrados na exposição verbal e na cópia - não forem substituídos por métodos novos, ativos, que permitam aprender com as coisas, manipulando-as, e não por meio de suas representações congeladas nos livros didáticos ou no quadronegro. Por outro lado, a disciplina não pode existir como algo imposto; precisa ser conquistada no ambiente escolar por meio de relações transparentes em que as responsabilidades de todos sejam discutidas e aceitas de boa vontade.

U ma crítica comumente dirigida à Escola N ova é a de que ela pretende ser um microcosmo da harmonia social. Ao conferir amplas liberdades ao aluno, tanto no que se refere aos planos de estudo quanto ao comportamento e aos costumes, faz-se da instituição escolar um oásis de entendimento, tolerância e facilidades que não são encontradas na sociedade real. Para os críticos, camufla-se o fato de que a escola reproduz as relações de dominação e a luta de classes, vendendo-se a ilusão de que ela corrigirá os males sociais na medida em que irá formar, com base na nova mentalidade, os futuros políticos, administradores, cientistas, professores etc. Em vista disso, tal escola diferiria em termos metodológicos da comeniana, mas seguiria tendo os mesmos propósitos éticos/morais que esta: formar o homem de bem e com ele a sociedade harmônica.

Sem dúvida, foram muito variadas as formas de implementação da Escola $\mathrm{N}$ ova em todo o mundo e o otimismo ingênuo pode ter marcado algumas experiências. Todavia, o cerne do pensamento de Dewey não parece ter sido a criação de escolas-modelo, na medida em que ele não via a educação escolar como preparação para um amanhã glorioso e sim como parte de um processo que se estende por toda a vida: 
Educar é extrair do presente a espécie e a potência de crescimento que este encerra dentro desi. Esta éuma função constante, independente da idade. A melhor coisa que se pode dizer a respeito de qualquer processo especial de educação, como o do período escolar formal, équeeletornao indivíduo capa citado para receber posterior educação, torna-o mais sensível às condições de crescimento emais capaz para delastirar vantagens. Aquisição dehabilidades, possedeconhecimentos, conquista decultura, não são fins, são antes balizas de crescimento emeios para a sua continuação. (D ewey, op. cit., p. 183)

Como a escola geralmente vê a si mesma como estádio preparador no qual o educando é apenas um vir-a-ser, isto é, um sujeito sem presente que vive a perspectiva de um futuro prometido, ela homogeneiza sua clientela segundo um padrão determinado: crianças do sexo masculino, brancas, de classe média e cristãs (Canen, 1997, p. 478).

A homogeneização faz com que apenas uma única cultura, a oficialmente transmitida pela escola, se imponha sobre outros padrões culturais (o indígena, o negro, o muçulmano etc.), abafando a manifestação de identidades diferentes. Esse processo leva também à marginalização dos saberes e das crenças que compõem aqueles padrões culturais, os quais são vistos como expressão da ignorância, do atraso, da superstição que devem ser erradicados. 0 professor homogeneizador encara, portanto, as mentes desses alunos como "folhas de papel ainda mais sujas" que as dos demais, nascidos no berço da cultura oficial. As concepções prévias são então mais arraigadas, as resistências à aprendizagem do que é tido por correto são maiores e os fracassos em termos de avaliação mais difíceis de evitar.

A homogeneização promovida tem ainda outra faceta, a do padrão ético/moral desejável para o aluno. A penas determinado tipo de conduta é aceita, sendo a transgressão das normas que a regulam imediatamente punida com rigor. Recentemente, no Rio de Janeiro, em um estabelecimento de ensino privado, cuja clientela é constituída por indivíduos procedentes da alta classe média, um grupo de estudantes foi sumariamente expulso após ter admitido o uso de maconha em uma excursão organizada pela escola. 0 fato, naturalmente, suscita uma questão: seriam certas faltas absolutamente más e a sinceridade em reconhecêlas de menor importância, ainda que útil?

A escola homogeneizadora tende a estabelecer hierarquias fixas de valores, as quais são objeto de consenso apenas quando expressas em termos abstratos, como por exemplo: sendo o bom sempre superior ao útil, seu contrário não pode ser compensado por este. Entretanto, quando tais valores se projetam sobre a realidade vivida pelos seres humanos 
é inevitável o surgimento de divergências, posto que diferentes interpretações acerca de um dado contexto são sempre factíveis. $\mathrm{N}$ a ausência de processos argumentativos, do confronto entre razões, segue então prevalecendo a frieza das normas.

$M$ as como o outro, o sem-razões, o homogeneizado, veria seus educadores? Sem dúvida, são necessárias pesquisas de campo para que se possa compor um perfil completo das opiniões discentes; contudo, uma pista interessante é fornecida pela canção Another brick in the wall - part 2, do grupo de rock inglês Pink Floyd (s.d., p. 114): Teachers leave the kids alone (...) all in all you're just another brick in the wall.

A condição de massa insípida e indiferenciada, como os tijolos que formam as paredes das escolas, por certo não agrada aos educadores. M uitos falam em mudanças e a proposta apresentada nos PCN s busca ser uma saída baseada no respeito à diversidade cultural e na tolerância em relação ao outro.

D e acordo com Canen (idem, p. 482-483), há duas formas de se tratar a questão da diversidade cultural. A primeira, chamada de aceitação, faz com que o contato com o outro se dê pela via da observação e da curiosidade: promovem-se, por exemplo, feiras de cultura ou atividades correlatas nas quais os alunos tomam conhecimento da existência de crenças, hábitos e valores diferentes daqueles difundidos pela cultura oficial. A referida autora destaca que, embora esse tipo de abordagem possa contribuir para combater preconceitos, é limitada, porquanto não avança na discussão acerca da marginalidade social em que se acham tais identidades.

O segundo modo de ver o problema é o correspondente a uma "perspectiva intercultural crítica" (ibid.), a qual situa a diversidade cultural em um contexto histórico-social. Q uestões como as relações de trabalho, as desigualdades econômicas, o desprestígio perante o padrão dominante, entre outras, são focalizadas. Tal abordagem permite que preconceitos ocultos venham à tona e que a idéia de superioridade da cultura oficial seja questionada. Assim, o respeito ao outro não é trabaIhado pela via da complacência piedosa (típica da aceitação) que veladamente 0 inferioriza, mas pela via do diálogo necessário entre sujeitos diferenciados. Por outro lado, a perspectiva intercultural crítica permite também problematizar posturas discriminatórias e preconceituosas existentes nas culturas marginalizadas. Justamente por não desqualificá-las a priori como inferiores e por não colocá-las em redomas de cristal, a perspectiva intercultural crítica abre discussões em que 0 dissenso pode ser profundamente enriquecedor para os interlocutores. 
Canen (op. cit., p. 489) salienta que o tom predominante no discurso dos PCN s é o da aceitação individual das diferenças culturais, não sendo enfatizada a dimensão das desigualdades sociais:

Em uma perspectivaintercultural crítica, um objetivo primordial deveriaenfatizar a desigualdade sócio-econômica como um dosfatores respon sáveis pela valorização diferencial deculturas, esclarecendo, destaforma, a não-superioridadede nenhuma etnia ou cultura sobrea outra, o quenão seobservaa nível de conteúdoseobjetivos propostosno documento.

N o que diz respeito à formação ética/moral do futuro cidadão, há também dois modos de conceber a tolerância em relação ao outro. Podese tomar a regra de ouro em um sentido preventivo: não fazer algo ruim, não molestar, não agredir para não sofrer ações recíprocas. Esse modo corresponde, no plano ético/moral, à aceitação cultural, na medida em que não estreita a relacionalidade humana, antes preservando espaços conquistados e limites de ação bem estabelecidos.

0 utra forma de se adotar a regra de ouro é aquela em que o sentido de interdição é retirado, tornando-a propositiva: fazer ao outro o que desejaríamos que ele nos fizesse. A princípio, tal positividade poderia sugerir apenas uma inversão da prescrição em termos genéricos, o que a tornaria semelhante a formulações do tipo "fazer o bem sem olhar a quem" ou "amar ao próximo como a si mesmo". Entretanto, se a supressão dos "nãos" for acompanhada por questões como "quais seriam os interesses do outro?" e "de que maneira o outro pode tomar conhecimento dos nossos interesses?", tem-se em vista a perspectiva dialógica. As diferenças passam então a ser problematizadas, o que significa confrontar as hierarquias de valores, os juízos e as ações praticadas por meio de processos argumentativos nos quais os interlocutores se coloquem ao mesmo tempo na situação de oradores e de auditório.

A problematização dos valores e das formas de conduta é apontada nos PCN s e vista como meta a ser al cançada pela ética na escola:

A éticaéum eterno pensar, refletir, construir. E, na escola, sua presença deve contribuir para que osalunos possam tomar partenessa construção, serem livres eautônomos para pensar ejulgar, para problematizar constantemente o viver pessoal ecoletivo, fazendo o exercício da cidadania. (Brasil, 1998, p. 24)

A concepção de cidadania presente no documento explicita que a situação desejável - embora não existente de fato na sociedade brasileira em razão das desigualdades econômicas - é aquela em que o sujeito autônomo, dotado de livre capacidade de escolha, se relaciona com 
outros nas mesmas condições. A escola é apresentada como espaço formativo responsável pelo aprendizado desses valores, mesmo que eles entrem em conflito com os existentes nos grupos sociais e/ou familiares dos quais os alunos fazem parte. Aqui, se observa a menção às desigualdades socioeconômicas do Brasil de hoje, mas a extensão em que elas afetam os contextos relacionais dos indivíduos não é particularmente discutida. Além disso, embora a escola não seja vista como o único locus onde ocorre a aprendizagem e a hierarquização dos valores, seu papel de liderança, sobretudo no que tange à formação dos espíritos democráticos, é ressaltado.

$\mathrm{N}$ ão há dúvida de que os PCN s avançam em muitos aspectos, tanto em relação às posturas ético/morais dogmáticas quanto em relação à omissão acerca da importância da ética/moral na escola. $M$ as o tom ufanista, que confere à educação escolar o papel de fiadora do futuro cidadão crítico, marca claramente o discurso:

E sem esperança, sem uma visão utópica, que acredita que a sociedade do futuro está no presente, perde se o sentido da construção conjunta da democracia. A esperançatransitanum espaço em quese coloca aos homenso desafio deconstruir o possível, criando uma sociedadena qual a questão da moralidade deveser uma questão detodosedecada um. (Idem, p. 29)

\section{Considerações finais}

A abordagem feita com base nos três eixos elencados está longe de esgotar as discussões sobre ética/moral na escola. D e todo modo, buscou apresentar um panorama da complexidade do tema, destacando que visões consensuais acerca da formação dos sujeitos éticos/morais são difíceis de serem estabelecidas.

Por mais que os manifestos e documentos elaborados pelos educadores tenham o objetivo de fazer da educação escolar um fundamento sólido de formação do caráter, haverá sempre hiatos entre as intenções e a realidade vivida por professores e alunos. Isso porque a capacidade de reflexão, o exercício da crítica, a autonomia, a liberdade de escolha e outras qualidades desejáveis não se configuram em aquisições inalienáveis do indivíduo. Pelo contrário, alteram-se de acordo com os contextos relacionais constituídos pelos homens. Já Aristóteles (1992, p. 35) afirmava que aprendemos as virtudes quando as praticamos, o que significa dizer: sem o exercício constante, vivenciado na realidade humano-social, as lições, os ensinamentos, os modelos, as prescrições perdem efetividade. 
Sendo o homem um ser dinâmico, ele se educa no convívio com os outros, em diferentes espaços sociais. Assim, a escola não se constitui no principal agente formador do caráter e da preparação para a cidadania. Suas contribuições são parte de um processo no qual intervêm múltiplos atores (a família, a roda de amigos, o grupo religioso etc.) e que tem lugar durante toda a vida. A formação ético-moral, portanto, não deve ser vista como meta fixa, mas como construção inacabada, cujo desenvolvimento não depende apenas da vontade soberana do indivíduo.

$\mathrm{N}$ a medida em que a relacionalidade é essencial no curso da existência, as práticas argumentativas colocam os homens na condição de oradores e de ouvintes, de persuasores e de persuadidos, de juízes que decidem sem que as certezas absolutas sejam avalistas das suas decisões. 0 recurso à argumentação e ao diálogo não é, como já foi dito, uma panacéia para todos os problemas éticos/morais, desigualdades sociais, conflitos e injustiças, permitindo, porém, chegar a soluções razoáveis para o momento vivido. $\mathrm{N}$ ão antecipa a história, mesmo porque esta é uma estrada cujo traçado incerto é feito pelos passos - às vezes largos, às vezes tímidos - do imprevisível animal humano.

Recebido para publicação em julho de 2001.

\section{N otas}

1. O termo é aqui utilizado no sentido de estudioso e praticante da $M$ oral e não no sentido pejorativo mais corriqueiro, referente à pessoa que deseja corrigir o comportamento e os hábitos dos outros.

2. O autor utiliza o termo estética em seu sentido grego original (aisthesis), que corresponde à sensibilidade e às paixões.

3. O livro de Lévy-Bruhl se intitula La morale et la science des moeurs, Paris: PUF, 1953.

4. Não é objetivo do presente artigo desenvolver essa questão, mas o termo se refere às dificuldades dos filósofos universalistas para enfrentar a crise das certezas no momento atual. Suas abordagens sempre deixam lacunas imensas quando tentam explicar a fragmentação do mundo apresentada pelos autores pós-modernos.

\section{Ethics AT SCHOOL: (RE) KINDLING A CONTROVERSY}

ABST RACT: Considering that Ethics at school and the education of student's character have been di scu ssed all over the world, thi spaper focuses its subject based on threeaxes. Thefirst onepresentssomephilosophical views on $\mathrm{M}$ orality and Ethics in order to investigate whether or not theoretical distinctionshavesocial impacts. T hesecond axisisrelated to thefoundations 
of M orality and Ethicsaspractical disciplines. Themain question is: Should general principles legitimatemoral/ethical judgments or viceversa? Finally the role assumed by school in the ethical/moral education of the citizen is explored. Both educational conceptions as those owing to Comenius and D ew ey and the homogenizing pedagogical practicesare discussed, as well as the ethical proposals included in the Parâmetros Curriculares $\mathrm{N}$ acionais ( $N$ ational Curricular Guidelines)

Key words: Ethi csat school; Education of human character; M oral/ethical principles, Arguments, $\mathrm{N}$ ational Curricular Guidelines.

\section{Referências bibliográficas}

ARIST Ó TELES. Ética a Nicômacos، 2ª ed. Braślia: Editora da UnB, 1992.

BENTHAM , Jeremy. U ma introdução aos princípios da moral e da legislação. In: O s Pensadores. Sã̃o Paulo: Abril Cultural, 1974, vol. 34 , p. 7-74.

BRASIL. Secretaria de Educação Fundamental. Parâmetros Curriculares nacionais: Terceiro e quarto ciclos; Apresentação dos temas transversais. Brasília: M EC/SEF, 1998, 436 p. [Versão disponibilizada na Internet pelo Sindicato das Escolas Particulares de Santa Catarina (Sinepe/SC ): www.sinepe-sc.org.br/5a8tt.htm].

CAN EN , Ana. Formação de professores: D iálogo das diferenças. Ensaio: Avaliação de políticas públicas em educação. Rio de Janeiro, out./ dez., 1997, vol. 5, no 17, p. 477-494.

CEN TER of the Advancement of Ethics and Character. $9^{\text {th }}$ Floor: Restructuring education. Seattle, 1999, 3p. [Versão disponibilizada na Internet: www. newhorizons.org/restr charman.html].

COM ÊN IO, João Amos. D idática magna. São Paulo: Martins Fontes, 1997.

DESCARTES, René. 0 discurso do método. São Paulo: M artins Fontes, 1996.

DEWEY, John. A filosofia em reconstrução. São Paulo: Companhia Editora N acional, 1958.

H ABERMAS, Jürgen. M oral consciousness and communicative action. Cambridge: Polity Press, 1990. 
H U M E, D avid. Investigación sobreel entendimi ento humano. Buenos Aires: Losada, 1950.

KAN T, Immanuel. Crítica da razão prática. Lisboa: Edições 70, 1997.

LALANDE, André. Vocabulário técnico e crítico da filosofia. São Paulo: M artins Fontes, 1993.

M AFFESO LI, M ichel. M affesoli ea crise da modernidade. In: W EYRAUCH, C.S. \& VincenZI, L.B. (O rgs.), M oderno e pós-moderno, Rio de Janeiro: Departamento Cultural da UERJ, 1994, p. 19-38.

MAZZOTTI, Tarso Bonilha \& OLIVEIRA, Renato José de. Ciência(s) da educação. Rio de Janeiro: D P\&A, 2000.

PERELM AN, Chaim. L'empire rhétorique. Paris: Vrin, 1988.

Ética e direito. São Paulo: M artins Fontes, 1996.

PERELMAN, Chaim \& OLBRECHTS-TYTECA, Lucie. Tratado da argumentação: A nova retórica. São Paulo: M artins Fontes, 1996.

PIN K FLO YD. A face oculta da lua - Poemas. Coimbra: Fora do Texto/ Cooperativa Editorial de Coimbra, s/d. 